\author{
Cristina Scheibe Wolff \\ Universidade Federal de Santa Catarina \\ Janine Gomes da Silva \\ Universidade Federal de Santa Catarina
}

Núcia A. S. de Oliveira

Universidade do Estado de Santa Catarina

\title{
Gênero, feminismos e ditaduras no Cone Sul: perspectivas recentes
}

(c) $(1)$ Esta obra tem licença Creative Commons.
Em 2014 tivemos no Brasil a (co)memoração dos 50 anos do golpe de Estado que instituiu uma ditadura que durou mais de vinte anos. Ao mesmo tempo, estávamos vivendo o processo de finalização do relatório da Comissão Nacional da Verdade, instituída em 2011 pelo governo brasileiro com o objetivo principal de investigar as violações de direitos humanos praticadas no Brasil no período de 1946 a 1988, e que se concentrou principalmente nesse período de ditadura. Esses dois fatos trouxeram à tona memórias, documentos e debates importantes sobre a questão da ditadura e de como ela atingiu pessoas e instituições no Brasil.

Muitas das pessoas presas, torturadas, desaparecidas ou atingidas através de seus familiares e amigos pela ditadura foram/são mulheres. No processo iniciado pela Comissão Nacional da Verdade, que se propalou para comissões estaduais, municipais e institucionais, mais do que nunca, os relatos de mulheres apareceram, e colocaram-se também outras questões que atingiram as discussões de gênero, como questões sobre o uso de tortura sexual, da tortura usando parceiros e parceiras, filhos e filhas, as prisões de familiares, entre outras.

Ao mesmo tempo que esses fatos estão ocorrendo no Brasil, nossos países vizinhos no Cone Sul vivem processos diversos de tratar com a memória do período, os quais envolvem julgamentos, como na Argentina, relatórios e outros processos de memória. O fato é que a ditadura brasileira não 
foi um fato isolado na América do Sul, mas uma das precursoras de tantas outras ditaduras de Segurança Nacional, que também têm sido chamadas de terrorismo de Estado.

Visando contribuir nos debates instaurados por conta da rememoração dos fatos relativos à instauração do regime militar no Brasil, pesquisadores/as, professores/as, estudantes e militantes de diferentes lugares do país e do Cone Sul reuniram-se no II Colóquio Internacional Gênero, Feminismos e Ditaduras no Cone Sul, que foi realizado entre os dias $11 \mathrm{e}$ 14 de agosto de 2014 no campus da Universidade Federal de Santa Catarina, na cidade de Florianópolis/SC.

Acompanhando as discussões propostas pela Comissão Nacional da Verdade e a visibilidade lançada sobre as questões relacionadas às diversas ditaduras estabelecidas em países como Brasil, Chile, Argentina e Uruguai, o evento buscou, especificamente, debater como o gênero esteve envolvido nas diversas dimensões políticas daqueles regimes. Também foi pretensão do referido colóquio lançar uma perspectiva transnacional sobre as ditaduras, os movimentos de resistência e suas articulações com os movimentos de mulheres e feministas.

A ideia da realização desse debate deve-se a um percurso de investigação e troca de experiências entre pesquisadores/as que tem sua origem junto ao Laboratório de Estudos de Gênero e História da Universidade Federal de Santa Catarina, que, desde $o$ ano de 2007, tem realizado pesquisas comparativas que enfocam o tema "Gênero, feminismos e ditaduras nos países do Cone Sul". Entre esses projetos estão "Vidas Clandestinas: relações de gênero na clandestinidade, um estudo comparativo no Cone Sul. (1960-1989)", coordenado por Joana Maria Pedro; "Lágrimas como bandeira: emoções e gênero na retórica da resistência no Cone Sul", coordenado por Cristina Scheibe Wolff; e "Espaços de memória: arquivos e fontes documentais (re)significando as ditaduras militares (Brasil e Paraguai)", coordenado por Janine Gomes da Silva. Além de vários projetos de doutorado, mestrado, trabalhos de conclusão de curso e iniciação científica. A equipe total dessa pesquisa conta com cerca de 20 pesquisadores.

Através dessas pesquisas, que têm contado com financiamentos do CNPq e da FAPESC, a equipe tem visitado os países do Cone Sul e entrado em contato com várias pesquisadoras, realizando entrevistas, coletando dados do período de 1960 a 1990 e adquirindo livros, e, no ano de 2009, com apoio da Secretaria de Políticas para as Mulheres, realizou o I Colóquio Internacional Gênero, Feminismos e Ditaduras no Cone Sul, no qual se buscou inverter o processo de saída do Brasil para a vinda ao país de pesquisadores/as que pudessem participar da formação de redes de pesquisadoras/

862 Estudos Feministas, Florianópolis, 23(3): 861-866, setembro-dezembro/2015 
es; a constituição de intercâmbios entre universidades e, principalmente, programas de pós-graduação; ainda, a elaboração de projetos coletivos de pesquisa, a troca de experiências e principalmente a formulação de novos conhecimentos sobre esse período da história recente em que os países do Cone Sul, e entre eles o Brasil, viveram processos semelhantes, porém, certamente reagiram a esses processos conforme suas configurações culturais, sociais e históricas.

A partir do I Colóquio, tais redes foram constituindo-se, e o campo das pesquisas com perspectiva de gênero enfocando o período das ditaduras no Cone Sul se ampliou consideravelmente. Resultados dessas redes têm sido não somente as pesquisas do Laboratório de Estudos de Gênero e História, como o livro Resistências, Gênero e Feminismos contra as Ditaduras no Cone Sul, publicado em 2011 pela Editora Mulheres, mas também publicações conjuntas, como o "Dossiê: Militância e vida cotidiana: os anos '60 e '70 no Cone Sul", publicado na Revista Interthesis e organizado em conjunto com Alejandra Oberti, Claudia Bacci e Mariella Peller, da Universidad de Buenos Aires.

Assim, no ano de 2014, quando a memória sobre o início do período ditatorial no Brasil esteve ressaltada pelo aniversário dos 50 anos do golpe de Estado, vislumbrou-se a oportunidade de dar continuidade ao projeto de pensar a questão dos regimes autoritários que se abateram sobre os países do Cone Sul nos anos 1960 e 1970 por uma perspectiva transnacional e que inclui, de maneira destacada, as políticas de gênero e a participação das mulheres na políitica. Nesse contexto, foi, portanto, proposta a realização do "II Colóquio Internacional Gênero, Feminismos e Ditaduras no Cone Sul", que, aliás, aconteceu juntamente com o "XV Encontro Estadual de História", organizado pela Associação Nacional de História Seção Santa Catarina (ANPUH-SC).

Nos quatro dias de debates, os/as participantes do Colóquio puderam vivenciar e trocar experiências de reflexão e aprendizagem sobre diferentes temáticas organizadas através de conferências, palestras, mesas redondas e simpósios temáticos que lançaram questões bastante diversificadas e relevantes para a articulação entre as temáticas gênero, feminismo e ditaduras. Destacaram-se discussões sobre as formas como as ditaduras nesses diversos países interferiram ou não nos movimentos feministas e de mulheres dos anos setenta e oitenta, na produção de mudanças ou permanências nas relações de gênero, e de que maneira os movimentos sociais e as próprias ditaduras utilizaram o gênero em suas estratégias discursivas e em suas práticas de luta e/ ou repressão, como viveram homens e mulheres suas trajetórias de luta e de exílio, a partir de uma perspectiva de gênero. 
A presente Seção Temática da Revista Estudos Feministas conta com artigos que iniciaram sua trajetória como apresentações nas mesas redondas do colóquio, porém foram desenvolvidos em forma de artigo por suas autoras, contando com o apoio e atenta avaliação das pareceristas consultadas pela revista. Cada artigo é, assim, fruto de um debate que envolveu a autora do texto e seu grupo de pesquisa, o público presente no colóquio, as pareceristas e as organizadoras da seção. Agradecemos a todas por seu trabalho de escrita, problematização, discussão e (re)escrita. São artigos que vêm de vários países do Cone Sul, mas que estão colocados em diálogo entre si e com a recente produção na área do feminismo e dos estudos de gênero no período dos anos 1960 a 1980.

O artigo "Fue bonita la solidaridad entre mujeres": género, resistencia, y prisión política en Chile durante la dictadura", foi escrito por Hilary Hiner, historiadora e professora na Universidad Diego Portales, em Santiago, Chile, a partir de uma pesquisa de história oral que realiza com mulheres sobreviventes das prisões políticas daquele país. Para analisar os depoimentos, a autora utiliza a teoria do gênero para discutir as formas pelas quais essas mulheres construíram sua experiência e sua memória como sobreviventes, de um lado, mas também como foi importante, para muitas delas, sua reconstrução como ativistas políticas, especialmente a partir do feminismo.

Em "¿Lo personal es político?: repensar la historia de las organizaciones político militares", a socióloga argentina Alejandra Oberti (Universidad de Buenos Aires) analisa diversos documentos internos e artigos da imprensa referentes a organizações armadas na Argentina, especialmente o Partido Revolucionario de los Trabajadores e seu braço armado Ejercito Revolucionário del Pueblo (PRT/ERP) e os Montoneros, Em sua discussão, a autora propõe-se a pensar que essas organizações não somente estavam propondo uma mudança social radical, mas que, em suas próprias práticas cotidianas, referentes, por exemplo, à conduta dos militantes, sua família e relações amorosas, procuravam empregar novas regras que corresponderiam a uma "moral revolucionária", transformadora. Faz, assim, de uma expressão de ordem feminista: "o pessoal é político", uma forma de analisar a política da época.

Quando se fala em ditadura e cinema, a grande tônica dos estudos tem sido enfatizar o trabalho da censura sobre os diversos meios de comunicação, o que nos leva a pensar que havia uma certa "onda moralizadora" exercida pelos governos ditatoriais. O texto "Paradojas del género y la sexualidad en la filmografía durante la última dictadura militar argentina", de Débora Carina D’Antonio, mostra, porém, uma

864 Estudos Feministas, Florianópolis, 23(3): 861-866, setembro-dezembro/2015 
certa contradição entre essa censura exercida pelo governo argentino e o financiamento e apoio que era dado à produção de filmes chamados lá de "sexicomédias", que devem ser semelhantes aos que, no Brasil, eram conhecidos como "pornochanchadas".

Em seu artigo "Nos habíamos amado tanto". Años revueltos. Mujeres, colectivos y la pelea por el espacio público", a historiadora uruguaia Graciela Sapriza faz uma história crítica do feminismo no Uruguai, que, por outro lado, se coaduna em muitos momentos com os feminismos que, nesses tempos de ditadura e pós-ditadura, vão se constituindo na região do Cone Sul. Os laços importantes entre os movimentos de esquerda e os nascentes coletivos e grupos de mulheres aparecem aí, bem como os limites impostos pela ditadura, as prisões, os exílios.

O artigo "El duelo callejero: mujeres, política y derechos humanos bajo la dictadura chilena (1973-1989)", de Carla Peñaloza, problematiza a luta das mulheres, muitas familiares de presos e desaparecidos, no Chile, que se tornam protagonistas políticas na luta pelo reconhecimento de suas mortes e pelo fim da violência política.

A historiadora brasileira Cristina Scheibe Wolff contribui para esse debate com o artigo "Pedaços de alma: emoções e gênero nos discursos da resistência". Nesse trabalho, a pesquisadora parte da análise de materiais organizados por familiares de presos e desaparecidos políticos e da reflexão sobre o uso político da emoção e do gênero como elementos de resistência. A intenção da autora, em suas próprias palavras, é mostrar "como as emoções e o gênero se entrelaçam em uma retórica que apela para os sentimentos da opinião pública com objetivos políticos." Segundo Wolff, a ênfase dada à exposição desses materiais buscava atingir o público, sensibilizando-o e, assim, estimulando-o ao combate e ao consequente enfraquecimento dos regimes militares.

O artigo de Flávia Schilling "Entre memórias, entre arquivos: por que não falar sobre o exílio?", e o de Maria Amélia de Almeida Teles, "Violações dos direitos humanos das mulheres na ditadura", finalizam a seção, juntando uma análise políitica e acadêmica com a perspectiva de pessoas que foram diretamente atingidas pelas ditaduras, tendo sido presas e torturadas: Flávia, apesar de brasileira, foi presa no Uruguai e Maria Amélia, no Brasil. Ambas tiveram também um importante papel na denúncia dos abusos das ditaduras.

Flávia Schilling, em sua narrativa, procura combinar a condição de testemunha com a reflexão sobre arquivos e memória. Para isso, seu texto é dividido em dois momentos: de início temos a proposta de pensar arquivo e memória em termos de espaço e motivação de pesquisa, e, num segundo momento, e a partir desses elementos, temos sua reflexão sobre 
o exílio. A partir de sua reflexão pessoal, a autora coloca com sensibilidade: "Para quem viveu, no dia a dia, a história do golpe e dos golpes de Estado na América Latina, o ano de 2014 foi, assim, difícil. Difícil, pois não importa a distância, não importa o tempo passado [...] tudo isso nos comove, nos balança, diz respeito. Não importa o tempo ou a distância, é quase impossível produzir a distância. Nos carrega e afeta."

O sentimento exposto no artigo Flávia Schilling é semeIhante ao feito na exposição oferecida por Maria Amélia Teles, que enfatiza a participação das mulheres na luta contra a ditadura no Brasil destacando como o sistema repressivo empreendeu sobre os corpos femininos ações de violência física e psicológica. Ela reflete como essas mulheres reconheceram na Comissão da Verdade o espaço político para falar em público sobre as violências sofridas, e reforça a necessidade de que tais crimes sejam devidamente investigados e as responsabilidades devidamente apuradas.

Os textos aqui publicados dão um bom panorama da produção recente sobre o tema "Gênero e Feminismo no período das ditaduras no Cone Sul", trazendo interfaces com a questão da construção da memória, dos direitos humanos, da produção cultural e do protagonismo político das mulheres.

866 Estudos Feministas, Florianópolis, 23(3): 861-866, setembro-dezembro/2015 